\title{
COMPARISON BETWEEN SPINAL ANAESTHESIA WITH PROPOFOL SEDATION AND GENERAL ANAESTHESIA IN CHILDREN OF 2-5 YEARS OF AGE UNDERGOING INFRAUMBILICAL SURGERIES
}

\author{
${ }^{1}$ Assistant Professor, Department of Anaesthesiology, Bankura Sammilani Medical College. \\ ${ }^{2}$ Assistant Professor, Department of Anaesthesiology, North Bengal Medical College. \\ ${ }^{3}$ Assistant Professor, Mata Gujri Memorial (MGM) Medical College, Kishanganj, Bihar. \\ ${ }_{4}^{4}$ Associate Professor, Department of Anaesthesiology, North Bengal Medical College. \\ 5 Professor, Department of Anaesthesiology, North Bengal Medical College.
}

Tirtha Ratan Ghosh¹, Subhrajyoti Chattopadhyay², Manasij Mitra ${ }^{3},{\text { Mohanchandra Mandal }{ }^{4} \text {, Sekhar Ranjan Basu }}^{5}$

ABSTRACT

\section{BACKGROUND}

Spinal anaesthesia enjoys certain advantages over general anaesthesia like avoidance of stress responses with airway manipulation and perioperative respiratory complications. Chances of hypotension and bradycardia are less in children due to sympathetic immaturity and smaller vascular bed in lower extremities in children. Very few studies are available comparing spinal and general anaesthesia in children.

\section{METHODS}

Eighty eight children aged 2-5 years of American Society of Anesthesiologists class I-II, posted for infraumbilical surgeries were randomly allocated into two groups to receive either spinal anaesthesia (Group $A, n=47$ ) or general anaesthesia (Group $B, n=41$ ) and was observed regarding postoperative analgesia in terms of the time to first analgesic requirement (Primary outcome), total analgesic requirement in 12 hours, haemodynamic stability and adverse events. Postoperatively, children with pain score of 3 or more on a 7 point Bieri face scale received paracetamol $15 \mathrm{mg} / \mathrm{kg}$ intramuscular or oral as appropriate as baseline analgesic and intravenous tramadol $1 \mathrm{mg} / \mathrm{kg}$ as rescue analgesic. Total consumption of paracetamol and tramadol in the first 12 hours of postoperative period was calculated.

\section{RESULTS}

The time to first analgesic requirement was longer in spinal anaesthesia $(\mathrm{P}<0.05)$. Total analgesic consumption and requirement of rescue analgesic were comparable. Haemodynamic stability was better in spinal anaesthesia. Better arterial oxygen saturati on was seen intraoperatively in general anaesthesia and postoperatively in spinal anaesthesia. Other adverse effects were comparable in both groups.

\section{CONCLUSION}

Spinal anaesthesia delays the first analgesic dose, provides better intraoperative haemodynamic stability, better postoperative arterial oxygen saturation than general anaesthesia. Other adverse effects were comparable.

\section{KEYWORDS}

Spinal Anaesthesia, General Anaesthesia, Paediatric Surgery, Postoperative Analgesia.

HOW TO CITE THIS ARTICLE: Ghosh TR, Chattopadhyay S, Mitra M, et al. Comparison between spinal anaesthesia with propofol sedation and general anaesthesia in children of 2-5 years of age undergoing infraumbilical surgeries. J. Evolution Med. Dent. Sci. 2016;5(51):3328-3332, DOI: 10.14260/jemds/2016/770

\section{INTRODUCTION}

Spinal Anaesthesia (SA) has been used in a scattered and infrequent way for paediatric population until 1984 when Abajian JC and coauthors.1,2 reported the effectiveness and safety of SA in high-risk infants. Thereafter, it has been successfully reintroduced and is gaining popularity. Spinal anaesthesia can avoid the potential complication of General Anaesthesia (GA) like the stress responses with airway manipulation and perioperative respiratory complications. ${ }^{2}$ SA related hypotension and bradycardia are less common in the paediatric population due to sympathetic immaturity,

Financial or Other, Competing Interest: None.

Submission 01-05-2016, Peer Review 03-06-2016,

Acceptance 09-06-2016, Published 27-06-2016.

Corresponding Author:

Dr. Subhrajyoti Chattopadhyay,

C/o. Mr. Satyajit Chakroborty,

Trinayani Apartment (2 ${ }^{\text {nd }}$ Floor),

Taltala, Arabinda Pally,

Siliguri-734006, West Bengal.

E-mail:drsubhra1972@gmail.com

DOI: $10.14260 /$ jemds $/ 2016 / 770$ diminished autonomic adaptability of the heart, smaller vascular bed in lower extremities. It also provides better analgesia in the immediate postoperative period. ${ }^{3}$

Moreover, spinal anaesthesia avoids complication related to drug metabolism as it usually avoids the use of multiple drugs. Presently, the problem of Post Dural Puncture Headache (PDPH) is also negligible due to availability of finer gauge, pencil-point spinal needle. SA produces relatively shorter duration of block in paediatric population compared to the adults due to higher cardiac output and regional blood flow. ${ }^{3}$

We hypothesized that children receiving SA would be benefitted with better analgesia in the first 12 hours compared to children receiving GA. Considering the above facts, the present study was performed for comparative analysis between spinal and general anaesthesia in children aged between 2 to 5 years for infraumbilical surgeries regarding postoperative analgesia in terms of the time to first analgesic requirement (Primary outcome), total analgesic requirement in 12 hours, haemodynamic stability and adverse events. 


\section{METHODS}

After getting the approval from Institutional Ethics Committee and written informed consent from the parents, 88 children of both sex, aged between 2 to 5 years, belonging to ASA physical status class I-II, posted for inguinal hernia repair, correction of hypospadias and lower limb surgeries were included for this randomized, open-label study. During pre-anaesthetic checkup, the following points were considered as the exclusion criteria for this study: parental denial, children with skin infection over the lower part of spine, spinal deformity, increased intracranial pressure, coagulopathy, cardiopulmonary and neurological diseases and history of allergy to any drug to be used for the procedure.

The children were randomly allocated to receive either spinal anaesthesia (Group A, n=47) or general anaesthesia (Group B, $n=41$ ). On the day of operation, the children were allowed to have clear fluid on demand until two hours before the surgery. Approximately, one hour before the surgery, Eutectic Mixture of Local Anaesthetics (EMLA) cream was applied locally over the selected sites for intravenous (IV) cannulation in children of both the groups and also at the expected site of lumbar puncture in children of group A. In the preoperative care room, children received premedication with oral midazolam $(0.5 \mathrm{mg} / \mathrm{kg})$ and the monitoring was started with precordial stethoscope and multichannel monitor with the facility of Electrocardiogram (ECG), Non-Invasive Blood Pressure (NIBP) and pulse oximeter. Preoperative Heart Rate (HR), Peripheral Arterial Oxygen Saturation $\left(\mathrm{SpO}_{2}\right)$ and Mean Arterial Pressure (MAP) were recorded. One intravenous line was established and infusion Lactated Ringer's Solution (RL) was started.

In group A, lumbar puncture was done with metal cannula of 24-gauge IV catheter in left lateral position using midline approach at $\mathrm{L}_{3-4}$ or $\mathrm{L}_{4-5}$ interspace. Just before the SA, additional sedation was given with IV propofol $(1 \mathrm{mg} / \mathrm{kg})$, if required. After confirmation of correct placement of spinal needle by the free flow of Cerebrospinal Fluid (CSF), 0.5\% bupivacaine hydrochloride heavy $0.5 \mathrm{mg} / \mathrm{kg}$ was injected. A 1 $\mathrm{mL}$ syringe was used to administer less than $1 \mathrm{~mL}$ of drug and $2 \mathrm{~mL}$ syringe was used for volume more than $1 \mathrm{~mL}$. After completion of injection the children were placed in supine, horizontal position. The level of sensory block was assessed with bilateral pin prick. Assessment of exact peak sensory block was not possible in most of the children due to the tender age. Hence, the facial expression suggestive of pain was taken as inadequate sensory block at the level of pin prick. Increase in HR, MAP or respiratory rate were also considered as the sign of inadequate block. It was not possible to assess the grade of motor block too. Surgeon was allowed to start the antiseptic draping after the sensory block was found sufficient for the respective operation. Child with inadequate sensory block was excluded from the study and managed with supplemental GA. Failure to perform the subarachnoid block was noted to calculate the success rate of block placement. Intraoperative sedation was given with propofol infusion at the rate of 10-50 $\mathrm{mcg} / \mathrm{kg} /$ minute titrated to keep the child quiet during operation. The level of peak sensory block and the time taken to reach peak sensory block could be assessed in a few children. At the end of operation, the children were again assessed for sensory block characteristics. Children with stable vitals, well controlled pain and at least two-segment block regression were discharged from operating room and were shifted to Post-Anaesthesia Care Unit (PACU). The time to reach peak sensory block, time for two-segment block regression were calculated from the completion of spinal injection.

In group $\mathrm{B}$, fentanyl $1 \mu \mathrm{gm} / \mathrm{kg}$ was given IV for intraoperative analgesia. Thereafter children were induced with IV propofol $1.5-2.5 \mathrm{mg} / \mathrm{kg}$, titrated to clinical effect. Atracurium $(0.5 \mathrm{mg} / \mathrm{kg})$ was given IV to facilitate intubation. Anaesthesia was maintained with nitrous oxide and oxygen (In $2: 1$ ratio) with initial frequency of ventilation 20 per minute and tidal volume of $8-10 \mathrm{~mL} / \mathrm{kg}$ using Mapleson-F breathing system. Fresh gas flow and minute ventilation was adjusted to maintain End-Tidal Carbon Di-Oxide $\left(\mathrm{EtCO}_{2}\right)$ around 35 mmHg. After confirmation of proper position and fixation of endotracheal tube, surgeons were allowed to start the operation. Muscle relaxation was maintained with IV top-up doses of atracurium $(0.1 \mathrm{mg} / \mathrm{kg})$ at intervals with the guidance of neuromuscular monitor. At the end of operation with the appearance of train-of-four (TOF) count 3, nitrous oxideoxygen mixture was replaced with $100 \%$ oxygen and the residual neuromuscular block was reversed with neostigmine and atropine in a dose of $50 \mathrm{mcg} / \mathrm{kg}$ and $20 \mathrm{mcg} / \mathrm{kg}$, respectively. After achieving TOF ratio 0.9 and sufficient recovery of sensorium, extubation was done. After extubation patients were assessed for respiration, maintenance of airway, $\mathrm{SpO}_{2}, \mathrm{HR}$ and blood pressure. Patients with stable vitals and adequate analgesia were shifted to PACU.

Heart rate, $\mathrm{SpO}_{2}$ and MAP were measured immediately after completion of subarachnoid block in group A. These parameters were measured immediately after induction of GA and after intubation in group $\mathrm{B}$. Thereafter $\mathrm{HR}, \mathrm{SpO}_{2}$, heart sound and breath sound were monitored continuously and MAP was monitored continually at 5 minutes interval. For comparison of haemodynamic stability, the HR and MAP at 15 minutes interval were documented. Any intraoperative episode of hypotension, hypertension, bradycardia and tachycardia were also accounted. Hypotension and hypertension were defined as $20 \%$ or more decrease or increase in baseline MAP, respectively. Bradycardia and tachycardia were defined as $20 \%$ or more decrease or increase in baseline heart rate, respectively. Hypotension was treated with a bolus infusion of $\mathrm{RL}(10 \mathrm{~mL} / \mathrm{kg}$ aliquots $)$ and bradycardia was treated with atropine $0.02 \mathrm{mg} / \mathrm{kg}$ IV. The episodes of hypertension and tachycardia were managed by titrating the infusion rate of propofol and with administration of further doses of analgesic or muscle relaxant as appropriate after analysing the causes. Intraoperative and postoperative $\mathrm{SpO}_{2}$, nausea-vomiting and any other adverse events were noted. Supplemental oxygen was given through transparent face mask when $\mathrm{SpO}_{2}$ was $<95 \%$. Surgeons were asked about their satisfaction regarding the anaesthetic procedure and they were requested to grade the procedure depending upon the obtained surgical condition as they feel in terms of 'fully satisfied,' 'moderately satisfied,' 'poorly satisfied' and 'dissatisfied.'

Postoperatively, pain was assessed with the help of 'Bieri face scale.' 4 a 7-point numeric scale of zero to six. The particular picture from Bieri face scale was identified that showed maximum similarity with the facial expression of the children. The number corroborative of that picture was considered as the pain intensity of the child at that point of time. 
For postoperative baseline analgesia, we used paracetamol $(15 \mathrm{mg} / \mathrm{kg})$, the initial dose as intramuscular and subsequent doses orally continued at 6 hour interval. We monitored patients continuously and assessed for pain frequently at 15 min interval to identify patients with pain score 3 or more and treated them with rescue analgesic (Intravenous tramadol 1 $\mathrm{mg} / \mathrm{kg}$ ). The time interval between the end of operation and first analgesic dose was noted as the time to first analgesia. Number of patients requiring tramadol were counted. Total consumption of paracetamol and tramadol in the first 12 hours of postoperative period was calculated. With this method the variation in pain score was minimal and in most of the patients the pain score remains less than 3 . Thus the variation of pain perception was not to be reflected by their pain score, rather it was better reflected by the analgesic requirement what we have measured in terms of analgesic requirement (Total paracetamol and tramadol in $24 \mathrm{hrs}$.) in the first 12 hours of postoperative period.

Considering that a $40 \%$ difference in the time to first analgesia in the postoperative period would be clinically relevant and assuming an $\alpha$-error of 0.05 and the power of study $(1-\beta)$ to be $80 \%$, we initially got a calculated sample size of 38 children for each group. Considering the chance of dropouts, a $15 \%$ excess patients were taken in each group. Thus we had a total of 88 children for two groups. They had undergone group allocation with lottery method on the day of surgery. The time to first analgesic requirement was set as primary outcome. Observations were tabulated in the Excel sheet and analysed with SPSS for windows (Version 12.0). Categorical data are presented as number of patients [n (\%)]; continuous data are expressed as mean \pm SD. Differences in demographic, surgical, intraoperative and postoperative data have been tested with independent-samples t-test (Continuous data) and Chi-square test (Categorical data). A ' $\mathrm{P}$ ' value $<0.05$ has been considered as statistically significant.

\section{RESULTS}

The study spanned from April 2009 to August 2010. Eighty eight children met the inclusion criteria. The two groups for intervention were: group $A(n=47)$, children received spinal anaesthesia and group $B(n=41)$ children received general anaesthesia. In group A for IV cannulation, one patient required inhalational anaesthesia in addition to topical anaesthesia and sedation with midazolam. This requirement of inhalational anaesthesia was a deviation from the study protocol and the child was excluded from the study. Two patients in group B were similarly excluded due to violation of study protocol. Placement of subarachnoid block was not possible in 2 of 46 children in group A. Thus, the success rate for subarachnoid block was $95.65 \%$. Those children were managed with GA and were excluded from the study. There was no inadequate block in patients of group A. Finally, 44 patients in group A and 39 patients in group B were available for followup, observation of different parameters and analysis (Fig. 1).

Demographic parameters and duration of operation were comparable in two groups (Table 1). As smaller children were unable to cooperate sufficiently for assessment of block characteristic, data regarding the peak sensory block were available only from 9 children. Among these nine children, four (9.1\%), two $(4.5 \%)$, one $(2.3 \%)$, one $(2.3 \%)$ and one $(2.3 \%)$ children had block heights up to $\mathrm{T}_{4}, \mathrm{~T}_{5}, \mathrm{~T}_{6}, \mathrm{~T}_{8}$ and $\mathrm{T}_{9}$ level, respectively. Mean time taken to reach the peak sensory block was $7.8 \pm 1.2$ minutes. For two-segment block regression, the mean time was $70 \pm 5$ minutes. Heart rates were comparable preoperatively at 15 minute and at 30 minute in two groups, but were higher in group B at 45 minutes and 60 minutes. MAP was higher in group $B$ throughout the operative period (Table 2). Episodes of bradycardia, tachycardia and hypertension were higher in group B (General anaesthesia). Episodes of hypotension were higher in spinal group, but not significant when analysed statistically. Hence, the haemodynamic status was more stable in spinal group. Intraoperative lower $\mathrm{SpO}_{2}$ was found more in children receiving SA. Postoperative lower $\mathrm{SpO}_{2}$ was observed more in children receiving GA. Shivering and vomiting were comparable in both groups (Table 3 ). Surgeons were fully satisfied with all 39 children under GA, but only with 37 of 44 children under SA. In rest of the cases under SA they were moderately satisfied. This difference is not statistically significant (Chi-square test, $\mathrm{P}>0.05$ ). Only the time to first analgesic requirement was significantly longer in spinal group. Other parameters like total paracetamol consumption, patients requiring rescue analgesic and consumption of tramadol as rescue analgesic were comparable in both the groups (Table 4).

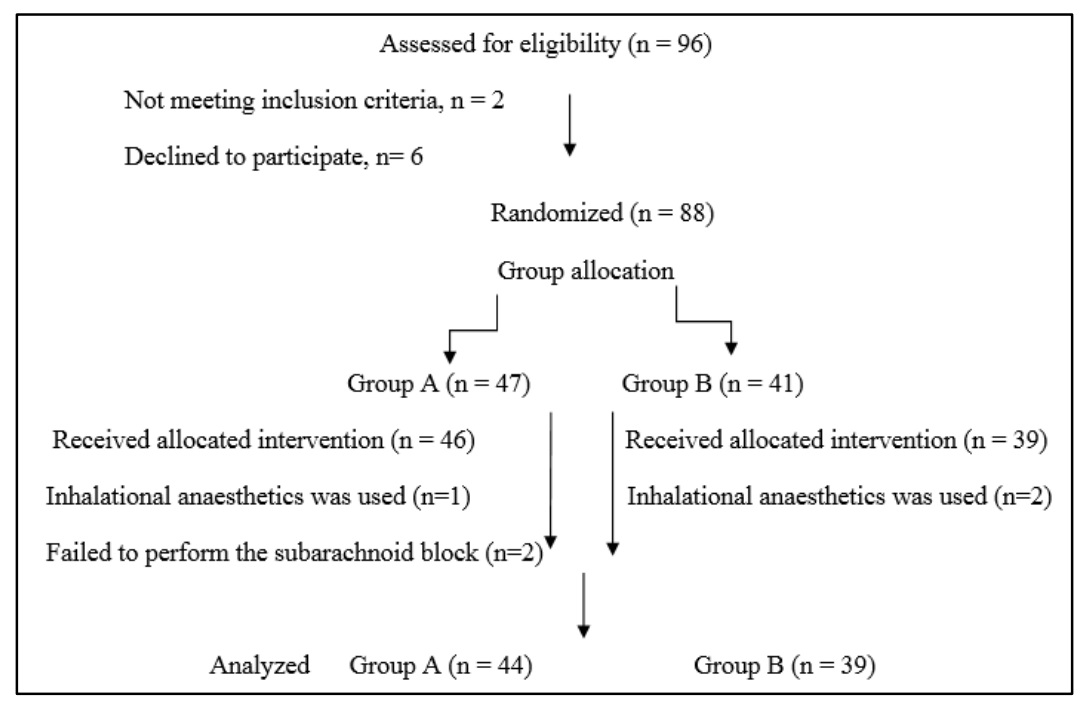

Fig. 1: Flow Diagram showing Patient Selection, Randomization and Lost to Follow-Up 


\begin{tabular}{|c|c|c|c|}
\hline Parameters & $\begin{array}{l}\text { Group A } \\
(n=44)\end{array}$ & $\begin{array}{l}\text { Group B } \\
(\mathrm{n}=39)\end{array}$ & $\begin{array}{c}P \\
\text { value }\end{array}$ \\
\hline Age (months) * & $33.1 \pm 9.4$ & $34.2 \pm 10.0$ & 0.47 \\
\hline $\operatorname{Sex}(M / F) \dagger$ & $40 / 4$ & $35 / 4$ & 1.00 \\
\hline Body weight $(\mathrm{kg})^{*}$ & $10.9 \pm 1.8$ & $11.4 \pm 2.0$ & 0.16 \\
\hline ASA status (I/ II) † & $44 / 0$ & $39 / 0$ & \\
\hline $\begin{array}{l}\text { Duration of } \\
\text { operation* }\end{array}$ & $43.3 \pm 9.1$ & $44.74 \pm 7.9$ & 0.43 \\
\hline
\end{tabular}

$*$, Continuous data represented as mean \pm SD, tested by independent-samples ' $\mathrm{t}$ ' test. $\mathrm{t}$, categorical data represented as number tested by Chi-square test. Group A, patients receiving spinal anaesthesia; Group B, patients receiving general anaesthesia; $\mathrm{P}<0.05$, statistically significant.

\section{Table 1: Demographic Profile}

\begin{tabular}{|c|c|c|c|}
\hline Parameters & $\begin{array}{l}\text { Group A } \\
(n=44)\end{array}$ & $\begin{array}{l}\text { Group B } \\
(n=39)\end{array}$ & $\begin{array}{c}P \\
\text { value }\end{array}$ \\
\hline $\begin{array}{l}\text { Preoperative } \\
\text { heart rate }\end{array}$ & $118.6 \pm 13.0$ & $116.3 \pm 12.8$ & 0.33 \\
\hline $\begin{array}{l}\text { Heart rate at } 15 \\
\text { minutes }\end{array}$ & $121.2 \pm 13.0$ & $118.1 \pm 12.5$ & 0.26 \\
\hline $\begin{array}{l}\text { Heart rate at } 30 \\
\text { minutes }\end{array}$ & $120.1 \pm 12.6$ & $119.5 \pm 13.0$ & 0.81 \\
\hline $\begin{array}{l}\text { Heart rate at } 45 \\
\text { minutes * }\end{array}$ & $119.7 \pm 10.8$ & $126.4 \pm 12.8$ & 0.02 \\
\hline $\begin{array}{l}\text { Heart rate at } 60 \\
\text { minutes } \dagger\end{array}$ & $117.1 \pm 13.3$ & $133.7 \pm 11.8$ & 0.00 \\
\hline $\begin{array}{l}\text { Preoperative } \\
\text { MAP }\end{array}$ & $76.1 \pm 8.1$ & $76.5 \pm 6.6$ & 0.71 \\
\hline $\begin{array}{l}\text { MAP at } 15 \\
\text { minutes }\end{array}$ & $68.7 \pm 9.0$ & $76.8 \pm 9.2$ & 0.00 \\
\hline $\begin{array}{l}\text { MAP at } 30 \\
\text { minutes }\end{array}$ & $70.5 \pm 9.2$ & $77.5 \pm 6.3$ & 0.00 \\
\hline $\begin{array}{l}\text { MAP at } 45 \\
\text { minutes * }\end{array}$ & $69.3 \pm 7.4$ & $82.9 \pm 8.4$ & 0.00 \\
\hline $\begin{array}{l}\text { MAP at } 60 \\
\text { minutes } \dagger\end{array}$ & $70.7 \pm 7.3$ & $83.9 \pm 12.3$ & 0.00 \\
\hline $\begin{array}{l}\text { Preoperative } \\
\mathrm{SpO}_{2}\end{array}$ & $99.6 \pm 0.7$ & $99.5 \pm 0.9$ & 0.87 \\
\hline $\begin{array}{l}\mathrm{SpO}_{2} \text { at } 15 \\
\text { minutes }\end{array}$ & $98.3 \pm 1.9$ & $99.2 \pm 1.0$ & 0.01 \\
\hline $\begin{array}{l}\mathrm{SpO}_{2} \text { at } 30 \\
\text { minutes }\end{array}$ & $98.6 \pm 1.5$ & $99.2 \pm 0.8$ & 0.01 \\
\hline $\begin{array}{l}\mathrm{SpO}_{2} \text { at } 45 \\
\text { minutes }\end{array}$ & $98.4 \pm 1.7$ & $99.2 \pm 1.0$ & 0.01 \\
\hline $\begin{array}{l}\mathrm{SpO}_{2} \text { at } 60 \\
\text { minutes } \dagger\end{array}$ & $99.0 \pm 1.0$ & $99.4 \pm 0.7$ & 0.23 \\
\hline
\end{tabular}

Data represented as mean $\pm S D$, tested by independentsamples ' $\mathrm{t}$ ' test. Number of patients available for observation varied as follows: *in group $A, n=38$ and in group $B, n=37$; tin group $A, n=13$ and in group $B, n=12$. Group A, patients received spinal anaesthesia; Group B, patients received general anaesthesia; $\mathrm{P}<0.05$, statistically significant; MAP, mean arterial pressure.

\section{Table 2: Preoperative and Intraoperative Parameters}

\begin{tabular}{|c|c|c|c|}
\hline Parameters & $\begin{array}{c}\text { Group A } \\
(\mathbf{n = ~ 4 4 )}\end{array}$ & $\begin{array}{c}\text { Group B } \\
(\mathbf{n}=\mathbf{3 9})\end{array}$ & $\begin{array}{c}\text { P } \\
\text { value }\end{array}$ \\
\hline \multicolumn{4}{|c|}{ Intraoperative } \\
\hline Bradycardia & 0 & 7 & 0.00 \\
\hline Tachycardia & 3 & 21 & 0.00 \\
\hline Hypotension & 9 & 4 & 0.36 \\
\hline Hypertension & 0 & 15 & 0.00 \\
\hline Decreased $\mathrm{SpO}_{2}$ & 8 & 0 & 0.01 \\
\hline
\end{tabular}

\begin{tabular}{|l|c|c|c|}
\hline \multicolumn{4}{|c|}{ Postoperative } \\
\hline Decreased $\mathrm{SpO}_{2}$ & 0 & 14 & 0.00 \\
\hline Shivering & 1 & 2 & 0.45 \\
\hline Vomiting & 2 & 4 & 0.45 \\
\hline Categorical data represented as number, tested by Chi- \\
square test. n, number of patients. Group A, patients \\
received spinal anaesthesia; Group B, patients received \\
general anaesthesia; $\mathrm{P}<0.05$, statistically significant. \\
\hline \multicolumn{4}{|c|}{ Table 3: Adverse Events } \\
\hline
\end{tabular}

\begin{tabular}{|l|c|c|c|}
\hline \multicolumn{1}{|c|}{ Parameters } & $\begin{array}{c}\text { Group A } \\
(\mathbf{n = 4 4 )}\end{array}$ & $\begin{array}{c}\text { Group B } \\
(\mathbf{n = 3 9 )}\end{array}$ & $\begin{array}{c}\text { P } \\
\text { value }\end{array}$ \\
\hline $\begin{array}{l}\text { Time to first } \\
\text { analgesic } \\
\text { requirement } \\
\text { (minutes) }\end{array}$ & $92.1 \pm 62.2$ & $24.7 \pm 9.9$ & 0.00 \\
\hline $\begin{array}{l}\text { Paracetamol } \\
\text { consumption (mg) } *\end{array}$ & $327.3 \pm 53.3$ & $342.3 \pm 59.1$ & 0.23 \\
\hline $\begin{array}{l}\text { No. of patients } \\
\text { required rescue } \\
\text { analgesic } \dagger\end{array}$ & 4 & 5 & 0.72 \\
\hline $\begin{array}{l}\text { Consumption of } \\
\text { rescue analgesic } \\
\text { tramadol in mg) }\end{array}$ & $1.0 \pm 3.3$ & $1.7 \pm 4.5$ & 0.45 \\
\hline . & & 5 & \\
\hline
\end{tabular}

$*$, Continuous data represented as mean \pm SD, tested by Independent-samples ' $t$ ' test. + Categorical data represented as number, tested by Chi-square test. Group A, patients receiving spinal anaesthesia; Group B, patients receiving general anaesthesia; $\mathrm{P}<0.05$, statistically significant. Table 4: Postoperative Analgesia

\section{DISCUSSION}

Practice of paediatric spinal anaesthesia is gradually gaining popularity. There are technical difficulties to establish the block due to problems in proper positioning and cooperation. Moreover, the movement of upper body-parts during operation in spite of good block is often embarrassing to anaesthesiologists. These may put some negative impact on its practice and popularity in the initial phase in any setup. However, the availability of EMLA cream, light general anaesthesia or sedation during and after the procedure, availability of reports mentioning less haemodynamic effects due to spinal anaesthesia ultimately have encouraged the present-day anaesthesiologists to consider spinal anaesthesia more frequently for their paediatric patients.

Present study was designed to compare postoperative analgesia, intraoperative haemodynamic stability and adverse effects between spinal and general anaesthesia in paediatric population (2-5 years). Spinal anaesthesia delayed the first dose of analgesic, but thereafter analgesic requirements were similar in both groups. Total consumption of paracetamol and tramadol in the first 12 hours of postoperative period was comparable. Kokki $\mathrm{H}$ and co-authors observed the time to first analgesia as 110 minutes. $^{5}$ (Median value) and 120 minutes. $^{6}$ (Median value) in spinal anaesthesia with hyperbaric bupivacaine in two consecutive studies. They used a dose of 0.5 $\mathrm{mg} / \mathrm{kg}$ for children weighing less than $10 \mathrm{~kg}$ and $0.4 \mathrm{mg} / \mathrm{kg}$ for children weighing 11 to $19 \mathrm{~kg}$ in one study. ${ }^{5}$ and a dose of 0.4 $\mathrm{mg} / \mathrm{kg}$ in another study. ${ }^{6}$ The time to first analgesic requirement in the current study (75 minutes, median value) is comparable to the earlier studies.5,6 
Slight higher dose of hyperbaric bupivacaine $(0.5 \mathrm{mg} / \mathrm{kg})$ was used in the present study compared to those earlier studies. Spinal anaesthesia produces relatively shorter duration of block in paediatric population compared to the adults due to higher cardiac output and regional blood flow. ${ }^{2}$ The duration long-acting local anaesthetics like bupivacaine is approximately 45 minutes in neonates and 75 to 90 minutes in children up to 5 years of age. Larger dose can increase this duration relatively. The duration varies directly with the age of the child.7 Dose of spinal anaesthetics is higher for paediatric age group due to higher amount of CSF content. ${ }^{8}$ The apparent difference in the pharmacokinetic behaviour of spinal anaesthesia between infants and adults can be attributed to the relative differences in the CSF volume, diameter and surface area of nerve roots and spinal cord and rates of absorption of local anaesthetics from the subarachnoid space. The volume of CSF is $4 \mathrm{~mL} / \mathrm{kg}$ in infants weighing less than 15 $\mathrm{kg}$, while in adults it is estimated to be approximately 2 $\mathrm{mL} / \mathrm{kg}$. ${ }^{9}$

Gupta A and coauthors. ${ }^{2}$ found that the time to first analgesic was significantly more in spinal anaesthesia group (3.7 hours) compared to general anaesthesia group, but the number of analgesic doses required in the first 24 hours were comparable in two groups. They conducted their study in a higher age group (1-12 years) and chose a lower dose of spinal drug $(0.3 \mathrm{mg} / \mathrm{kg})$ than the present study (Children between 25 years and dose of spinal drug as $0.5 \mathrm{mg} / \mathrm{kg}$ ). The longer duration of spinal analgesia can be attributed to higher age group in their study leading to longer time to first analgesic (3.7 \pm 2.3 hours) compared to the present study $(92.1 \pm 62.2$ minutes). But the total analgesic dose requirement in the postoperative period corroborates with the present study.

The current study finds better haemodynamic stability with spinal anaesthesia than general anaesthesia. Reduction of blood pressure and heart rate due to block of sympathetic fibers are less marked due to immature sympathetic system in paediatric patients. Pharmacological sympathectomy practically puts no physiological impact in children less than 5 years old. ${ }^{2,7}$ Intraoperative $\mathrm{SpO}_{2}$ was lower in group A (Spinal anaesthesia) compared to group B (General anaesthesia) who received controlled ventilation. This is possibly due to the respiratory depression with propofol sedation in spontaneously breathing patients in group A.

Shivering and vomiting in both the groups, intraoperative lower $\mathrm{SpO}_{2}$ in group $\mathrm{A}$ and postoperative lower $\mathrm{SpO}_{2}$ in group $\mathrm{B}$ were the adverse events found in our study. Kokki $\mathrm{H}$ and Coauthors. ${ }^{10}$ reported postoperative oxygen desaturation, vomiting, sore throat and micturition difficulties in 11, 2, 4 and 2 of 20 children who received GA.

Limitations in the present study include the use of a metal cannula of 24-gauge intravenous catheter used for lumbar puncture due to unavailability of $5 \mathrm{~cm}$ long (Paediatric variety) Quincke spinal needle. Unfortunately, the injectable form of midazolam hydrochloride was used orally after mixing it with sugar simplex syrup as the oral preparation was not available in this region during the study period. The small number of verbal children in whom the height completeness of the spinal block and comfort could be assessed. We could not assess the incidence of PDPH too. If the analgesic consumption in the total postoperative period could have been compared, it might have revealed any long-term effects of spinal anaesthesia on analgesic requirement, which was beyond the scope of this study. So an adequately powered study evaluating the analgesic requirement in the immediate postoperative period as well as the total postoperative period will be of value to evaluate the effectiveness of spinal and general anaesthesia in paediatric age group. At the time of reporting, syrup form of midazolam is available.

The present study concludes that the time to first analgesic requirement is longer in spinal anaesthesia compared to general anaesthesia, but the total analgesic requirement in the first twelve hours of postoperative period is comparable. Spinal anaesthesia with propofol sedation provides better intraoperative haemodynamic stability and also better postoperative arterial oxygen saturation than general anaesthesia. Other adverse effects are comparable.

\section{REFERENCES}

1. Williams RK, Adams DC, Aladjem EV, et al. The safety and efficacy of spinal anaesthesia for surgery in infants: the vermont infant spinal registry. Anaesth Analg 2006;102(1):67-71.

2. Gupta A, Saha U, Sinha SK, et al. Subarachnoid block (SAB) versus general anaesthesia (GA) in children undergoing surgeries below umbilicus. J Anaesth Clin Pharmacol 2008;24:425-8.

3. Kokki H, Hendolin H, Trunen M. Postdural puncture headache and transient neurologic symptoms in children after spinal anaesthesia using cutting and pencil point paediatric spinal needles. Acta Anaesthesiol Scand 1998;42(9):1076-82.

4. Weisman SJ, Rusy LM. Pain management in infant and children. In: Matoyama EK, Davis PJ, editors. Smith's anaesthesia for infants and children. $7^{\text {th }}$ ed. Philadelphia: Mosby Elsevier 2006:436-58.

5. Kokki H, Tuovinen K, Hendolin H. Spinal anaesthesia for paediatric day-case surgery: a double-blind, randomized, parallel group, prospective comparison of isobaric and hyperbaric bupivacaine. Br J Anaesth 1998;81(4):502-6.

6. Kokki H, Hendolin H. No difference between bupivacaine in $0.9 \%$ and $8 \%$ glucose for spinal anaesthesia in small children. Acta Anaesthesiol Scand 2000;44(5):548-51.

7. Goyal R, Jinjil K, Baj BB, et al. Paediatric spinal anaesthesia. Indian Journal of Anaesthesia 2008;52(3):264-72.

8. Dalens BJ. Regional anaesthesia in children. In: Miller RD, Eriksson LI, Fleisher LA, et al. (editors). Miller's Anaesthesia. $7^{\text {th }}$ ed. Philadelphia: Churchill Livingstone, an imprint of Elsevier Inc 2010:2519-58.

9. Webster AC, McKishnie JD, Kenyon CF, et al. Spinal anaesthesia for inguinal hernia repair in high-risk neonates. Can J Anaesth 1991;38(3):281-6.

10. Kokki H, Hendolin H, Vainio J, et al. Paediatric surgery. A comparison of spinal anaesthesia and general anaesthesia. Anaesthesist 1992;41(12):765-8. 